\title{
Parameter Identification of Bladed Assemblies Using a Subspace Method
}

\author{
Bendali Salhi, Joseph Lardiès, and Marc Berthillier \\ Institute FEMTO-ST; UMR-CNRS 6174-Department LMARC, 25000, Besancon, France
}

Received 02 April 2008, Accepted 17 August 2008

\begin{abstract}
This paper is aimed at identifying a dynamical model for bladed assemblies such as turbines. Unknown excitation forces are applied to bladed disk assemblies leading to forced vibration responses. Non contact measurement of such vibrations using tip-timing has become an industrial standard procedure and current research focuses on analysis methods for interpretation of measured vibrations. Our purpose is to develop a subspace method for the identification of blade's natural frequencies, damping ratios and mode shapes using blade tip-timing data. The importance of the developed procedure results in the fact that in a narrow band frequency, less than $2 \mathrm{~Hz}$, twenty two modes can be easily identified. A detailed description of this method and results are presented.
\end{abstract}

Key words: Modal parameters, Subspace method, Bladed disk assemblies, Aliasing, Signal reconstruction

\section{Introduction}

Bladed assemblies such as turbines are subject to several sources of excitation leading to forced vibration responses that appear near of blade's natural frequencies. Such structural vibration can affect the fatigue life, performance and integrity of bladed assemblies. Generally, blade vibrations during operation are difficult to measure and require many sensors in order to be detected fully. Two standard measuring methods are used to obtain blade vibrations: strain gages and frequency-modulated grid systems [1-3]. The first method requires the installation of strain gages on some of the blades. This is a very expensive process since it requires slip rings or high-quality telemetry and long installation times. For the second standard method, the frequency modulated grid systems, permanent magnets are fitted on the tips of some blades and a specially formed wire is installed in the compressor casing above the magnets. As a blade passes a wire, the magnet produces an alternating current in the wire. Blade vibrations are interpreted from the voltage modulation of this signal. No signal transmitter between the rotor and the stator is needed, but the wire requires a special casing and the number of blades monitored at a time is limited to three per rotor stage. An alternative method to the two standard measurement methods is the blade tip-timing (BTT) technique or non intrusive stress measurement which is based on optical, capacitive or magnetic probe technology. This method is briefly presented in section 2 . To obtain the modal parameters of rotating bladed assemblies from BTT data a subspace method [4-5], which is an in-operation system identification method, is proposed. The ambient input is unknown and the subspace identification algorithm has to deal with outputonly measurements. The basic description of the subspace identification method is to use a finite dimensional, discrete time, linear, time-invariant dynamic system to construct a sequence of real matrices known as Markov parameters. From these known parameters and using the singular value decomposition technique [6] we can identify the modal pa- rameters of bladed assemblies. The subspace identification technique has recently attracted much attention owing to its advantages over traditional techniques such as the prediction error method. The prediction error method has problems of convergence and long running time as the number of parameters to identify becomes large. The subspace method does not entail such difficulties as the number of parameters increases, which often makes it more suitable for multi output system identification. This paper presents a contribution to the modal analysis of rotating machines using non contact measurements.

\section{The blade tip-timing method}

The basic concept of the blade tip-timing method has been developed in [1-3]. Several probes are installed in the engine casing above the rotor, and the blade transit times between the probes are measured. The basic principle of the method can be summarized as follows: two sensors are placed around the blades and they measure the passage time of each blade in front of the sensors. The angle between these two sensors is $180^{\circ}$. A third sensor is placed in the proximity of the engine shaft. It measures the once-per-revolution signal. When there are no blade vibrations, the blade transit times are a function of rotor speed, rotor radius and circumferential probe position. In the case of blade vibrations, the blade transit times deviate from those obtained in the undisturbed condition, with the blades passing the probes earlier or later than normal, depending on their instantaneous deflection. This technique provides notable advantages: it is non-contacting, it senses all blades and it reduces costs because it eliminates the need for rotor instrumentation and telemetry for signal transmission. However, one drawback is that the measurement sampling frequency is completely dependent of the rotor speed and the number of measurement probes.

Methods for analyzing blade tip timing data have been developed since 1970. However, given a limited number of probes, there are still no standard approaches that can identify synchronous response resonance frequencies with ade- 
quate precisions. Let us recall that synchronous response occurs when a blade's vibration frequency is an integer multiple of the engine rotation speed and asynchronous response occurs when the blades frequency response is a non-integer multiple of the assembly rotation speed. Synchronous vibration can be caused by mechanical effects such as residual unbalance of the rotors and non-concentric casing, as well as aerodynamic effects. Asynchronous vibrations are typically caused by flutter, rotating stall, or by acoustic resonance. From experimental point of view, the problem is that it is impossible to know with enough accuracy which blade will produce the largest vibration amplitude. As rotating instrumentation is limited, a challenge for the monitoring of bladed assemblies such as turbines is the analysis of blade tip timing data.

\section{The mathematical model}

The blade tip timing data analysis method developed in this paper is applied to simulated time data obtained from a mathematical model of the forced response of a rotating bladed assembly. Figure 2 shows the basic layout of the mechanical model. For illustrative purposes only three blades represented by a mass-spring-damper system are shown in this figure and it is assumed that each blade in the assembly has one significant mode which is the first bending.

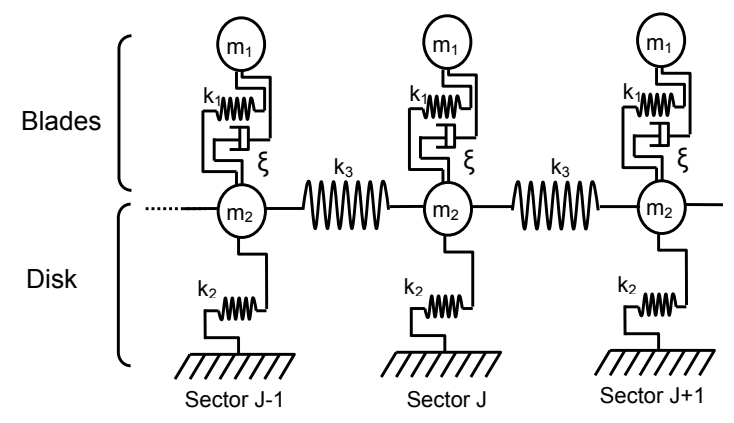

Fig. 1 Two degrees of freedom per sector model

This system has blade degrees of freedom (DOF) and disk (DOF) for each sector. Each disk is coupled to neighboring sectors by springs of stiffness $\mathrm{k}_{\mathrm{c}}$. A structural damping, whose damping ratio is $\xi$, is shown in the model. This model simulates the dynamic behavior of a blade assembly which has twenty two blades, and provides a temporal forced response of each blade. Random excitations are generated to obtain the forced responses of the system and only steadystate responses are considered for the identification of modal parameters. This model will provide the temporal forced response of each blade. The equations of motion for this model are:

$$
\mathrm{M}_{0} \ddot{\mathrm{q}}(\mathrm{t})+\mathrm{C}_{0} \dot{\mathrm{q}}(\mathrm{t})+\mathrm{K}_{0} \mathrm{q}(\mathrm{t})=\mathrm{F}(\mathrm{t})_{\text {aeroelastic }}+\mathrm{F}(\mathrm{t})_{\text {aerodynamic }}
$$

where $\mathrm{q}(\mathrm{t})$ is the vector of displacements corresponding to the $2 \times 22$ degrees of freedom.

We pose $\eta(\mathrm{t})=\mathrm{F}(\mathrm{t})_{\text {aeroelastic }}+\mathrm{F}(\mathrm{t})_{\text {aerodynamic }}$. The displacement in sector $\mathrm{j}$ is given by $\mathrm{q}^{\mathrm{j}}(\mathrm{t})=\left(\begin{array}{l}\mathrm{q}_{1}^{\mathrm{j}}(\mathrm{t}) \\ \mathrm{q}_{2}^{\mathrm{j}}(\mathrm{t})\end{array}\right)$, the subscript 1 represents the blade and the subscript 2 represents the disk. In fact, the displacement for all sectors is given by the global
$(44 \times 1)$ vector $: \mathrm{q}(\mathrm{t})=\left(\begin{array}{c}\mathrm{q}^{1}(\mathrm{t}) \\ \cdot \\ \cdot \\ \mathrm{q}^{44}(\mathrm{t})\end{array}\right) ; \mathrm{M}_{0}, \mathrm{C}_{0}$ and $\mathrm{K}_{0}$ represent

the structural mass, damping and stiffness matrices of dimension (n' $x$ n') with $n$ ' $=44$. The mass matrix $M_{0}$ is given by

$$
\begin{aligned}
& \mathrm{M}_{0}=\left[\begin{array}{cccc}
\mathrm{M}_{\mathrm{a}} & 0 & \cdot & 0 \\
0 & \mathrm{M}_{\mathrm{a}} & \cdot & 0 \\
\cdot & \cdot & \cdot & \cdot \\
0 & 0 & 0 & \mathrm{M}_{\mathrm{a}}
\end{array}\right] \\
& \text { with } \mathrm{M}_{\mathrm{a}}=\left[\begin{array}{cc}
\mathrm{m}_{1} & 0 \\
0 & \mathrm{~m}_{2}
\end{array}\right]
\end{aligned}
$$

The stiffness matrix $\mathrm{K}_{0}$ is given by

$$
\mathrm{K}_{0}=\left[\begin{array}{ccccc}
\mathrm{K}^{\prime} & \mathrm{K}^{\prime \prime} & 0 & \cdot & \mathrm{K}^{\prime \prime} \\
\mathrm{K}^{\prime \prime} & \mathrm{K}^{\prime} & \mathrm{K}^{\prime \prime} & \cdot & 0 \\
0 & \mathrm{~K}^{\prime \prime} & \mathrm{K}^{\prime} & \cdot & 0 \\
\cdot & \cdot & \cdot & \cdot & \cdot \\
\mathrm{K}^{\prime \prime} & 0 & \cdot & \mathrm{K}^{\prime \prime} & \mathrm{K}^{\prime}
\end{array}\right]
$$

with $\mathrm{K}^{\prime}=\left[\begin{array}{cc}\mathrm{k}_{1} & -\mathrm{k}_{1} \\ -\mathrm{k}_{1} & \mathrm{k}_{1}+\mathrm{k}_{2}+2 \mathrm{k}_{3}\end{array}\right] ; \mathrm{K}^{\prime},=\left[\begin{array}{cc}0 & 0 \\ 0 & -\mathrm{k}_{3}\end{array}\right]$

The damping matrix is given by

$$
\mathrm{C}_{0}=\mathrm{P}^{-\mathrm{T}} \operatorname{diag}\left(4 \pi \xi_{\mathrm{i}} \mathrm{f}_{\mathrm{i}}\right) \mathrm{P}^{-1}
$$

where $f_{i}$ is the $i^{\text {th }}$ natural frequency, $\xi_{i}$ is the $i^{\text {th }}$ damping ratio and $\mathrm{P}$ is the matrix containing the conservative mode shapes. An aeroelastic force $\mathrm{F}(\mathrm{t})_{\text {aeroelastic }}$ has been introduced in the model, in the way of circulant matrices coefficients, considering only five different coefficients [7]. This aeroelastic force has been computed with a software developed by our research group. A white noise excitation simulates the aerodynamic forces $F(t)_{\text {aerodynamic }}$ and generates the time forced response. It is representative of turbulent excitation of the blades. The stiffness coefficients have been chosen in order that the blade modes are well separated from the disk modes: the blade modes family has frequencies around $60 \mathrm{~Hz}$ and the lowest frequency for a disk mode is close to $500 \mathrm{~Hz}$. This tuned model is mistuned by the introduction of a different stiffness for each blade : $\mathrm{k}_{1, \mathrm{i}}=\mathrm{k}_{1}\left(1+\delta_{\mathrm{i}}\right)$, with $\mathrm{i}=1$, 22 , where $\delta_{\mathrm{i}}$ is the $\mathrm{i}^{\text {th }}$ mistuning value which is given randomly.

Let $m$ be the number of blades $(m=22)$. To equation (1) is added the (mx1) observation equation [4]

$$
y(t)=L q(t)+v(t)
$$

where L is the (mxn') output influence matrix for the displacement, describing the relationship between the vector $\mathrm{q}(\mathrm{t})$ and the measurement vector $\mathrm{y}(\mathrm{t})$ and $\mathrm{v}(\mathrm{t})$ is an $(\mathrm{mx} 1)$ additive noise disturbance, a vector of measurement errors 
simulated by a gaussian white noise. The modal characteristics $(\mu, \Psi)$ of the vibrating system are solutions of:

$$
\operatorname{det}\left(\mathrm{M}_{\mathrm{o}} \mu^{2}+\mathrm{C}_{\mathrm{o}} \mu+\mathrm{K}_{\mathrm{o}}\right)=0 ;\left(\mathrm{M}_{\mathrm{o}} \mu^{2}+\mathrm{C}_{\mathrm{o}} \mu+\mathrm{K}_{\mathrm{o}}\right) \Psi=0
$$

where det( ) represents a determinant.

The system described by (1) and (6) is equivalent to the following continuous time state-space model [4]:

$$
\begin{array}{r}
\dot{x}(t)=\widetilde{A} x(t)+\widetilde{B} \eta(t) \\
y(t)=C x(t)+v(t)
\end{array}
$$

where $x(t)$ is the state vector of dimension $2 n^{\prime}=n$

$$
x(t)=\left[\begin{array}{c}
q(t) \\
\dot{q}(t)
\end{array}\right]
$$

$\widetilde{A}$ is the $n$ by $n$ state matrix, $\widetilde{B}$ is the $n$ by n' matrix containing the bloc matrix $\mathrm{M}_{\mathrm{o}}^{-1}$ and $\mathrm{C}$ is the $\mathrm{m}$ by $\mathrm{n}$ output influence matrix including displacement only

$$
\begin{aligned}
& \widetilde{\mathrm{A}}=\left[\begin{array}{cc}
0 & { }^{\mathrm{I}} \\
-\mathrm{M}_{\mathrm{O}}{ }^{-1} \mathrm{~K}_{\mathrm{O}} & -\mathrm{M}_{\mathrm{O}}{ }^{-1} \mathrm{C}_{\mathrm{O}}
\end{array}\right] ; \quad \widetilde{\mathrm{B}}=\left[\begin{array}{c}
0 \\
\mathrm{M}_{\mathrm{O}}{ }^{-1}
\end{array}\right] ; \\
& \mathrm{C}=\left[\begin{array}{ll}
\mathrm{L} & 0
\end{array}\right]
\end{aligned}
$$

Equations (8) and (9) constitute a continuous time state space model of the dynamical system and the order of the system is the dimension of the state matrix. Given the initial condition $\mathrm{x}\left(\mathrm{t}_{0}\right)$ at some $\mathrm{t}=\mathrm{t}_{0}$ and solving for $\mathrm{x}(\mathrm{t})$ from equation (8) yields

$$
x(t)=e^{\tilde{A}\left(t-t_{0}\right)} x\left(t_{0}\right)+\int_{t_{0}}^{t} e^{\tilde{A}(t-\tau)} \tilde{B} \eta(\tau) d \tau
$$

This equation describes the variation with time of the state variable $x(t)$ with respect to the initial condition $x\left(t_{0}\right)$ and the input $\eta(t)$. The evaluation of $x(t)$ at equally spaced intervals of time $t$ can be obtained by a discrete time representation of equation (12). Let the equally spaced times be given by 0 , $\Delta \mathrm{t}, 2 \Delta \mathrm{t}, \ldots,(\mathrm{k}+1) \Delta \mathrm{t}, \ldots$ where $\Delta \mathrm{t}$ is a constant sampling period. Consider $\mathrm{t}=(\mathrm{k}+1) \Delta \mathrm{t}$ and $\mathrm{t}_{0}=\mathrm{k} \Delta \mathrm{t}$, equation (12) becomes

$\mathrm{x}[(\mathrm{k}+1) \Delta \mathrm{t}]=\mathrm{e}^{\tilde{\mathrm{A}} \Delta \mathrm{t}} \mathrm{x}(\mathrm{k} \Delta \mathrm{t})+\int_{\mathrm{k} \Delta \mathrm{t}}^{(\mathrm{k}+1) \Delta \mathrm{t}} \mathrm{e}^{\tilde{\mathrm{A}}[(\mathrm{k}+1) \Delta \mathrm{t}-\tau]} \tilde{\mathrm{B}} \eta(\tau) \mathrm{d} \tau$

Now, we define $A=e^{\widetilde{A} \Delta t}$ the (nxn) discrete time statespace matrix, $x_{k+1}=x[(k+1) \Delta t]$ the discrete time state vector and $\mathrm{u}_{\mathrm{k}}=\int_{\mathrm{k} \Delta \mathrm{t}}^{(\mathrm{k}+1) \Delta \mathrm{t}} \mathrm{e}^{\tilde{\mathrm{A}}[(\mathrm{k}+1) \Delta \mathrm{t}-\tau]} \tilde{\mathrm{B}} \eta(\tau) \mathrm{d} \tau$ the global input vector. We obtain the following discrete time state-space model

$$
\begin{gathered}
\mathrm{x}_{\mathrm{k}+1}=\mathrm{A} \mathrm{x}_{\mathrm{k}}+\mathrm{u}_{\mathrm{k}} \\
\mathrm{y}_{\mathrm{k}}=\mathrm{C} \mathrm{x}_{\mathrm{k}}+\mathrm{v}_{\mathrm{k}}
\end{gathered}
$$

$\mathrm{y}_{\mathrm{k}}$ is the discrete time observation equation or output observation vector. The time responses of 22 blades are used in the identification process and the two discrete previous equations form the basis for the system identification procedure.

\section{Identification of modal parameters}

The matrix (nxn) of eigenvalues $\lambda$ and the matrix (nxn) of eigenvectors $\Phi$ of the discrete time transition matrix A are related to the modal characteristics (7) by [9-10]

$$
\lambda=\mathrm{e}^{\mu \Delta \mathrm{t}} \text { and } \mathrm{C} \Phi=\mathrm{L} \Psi
$$

The global modal parameters: the natural frequencies $f_{i}$ and damping ratios $\xi_{\mathrm{i}}$ of the vibrating system can be determined by

$$
\begin{aligned}
& \mathrm{f}_{\mathrm{i}}=\frac{1}{2 \pi \Delta \mathrm{t}} \sqrt{\frac{\left[\ln \left(\lambda_{\mathrm{i}} \lambda_{\mathrm{i}}^{*}\right)\right]^{2}}{4}+\left[\cos ^{-1}\left(\frac{\lambda_{\mathrm{i}}+\lambda_{\mathrm{i}}^{*}}{2 \sqrt{\lambda_{\mathrm{i}} \lambda_{\mathrm{i}}{ }^{*}}}\right)\right]^{2}} \\
& \zeta_{\mathrm{i}}=\frac{1}{2 \pi \Delta \mathrm{t}} \sqrt{\frac{\left[\ln \left(\lambda_{\mathrm{i}} \lambda_{\mathrm{i}}^{*}\right)\right]^{2}}{4}+\left[\cos ^{-1}\left(\frac{\lambda_{\mathrm{i}}+\lambda_{\mathrm{i}}^{*}}{2 \sqrt{\lambda_{\mathrm{i}} \lambda_{\mathrm{i}}^{*}}}\right)\right]^{2}}
\end{aligned}
$$

for $\mathrm{i}=1,2, \ldots . \mathrm{n}$ '

Our objective is to obtain the discrete time transition matrix A (nxn) from the output observation vector $y_{k}(m x 1)$. Define $\mathrm{y}_{\mathrm{k}}^{+}=\left[\mathrm{y}^{\mathrm{T}}{ }_{\mathrm{k}}, \mathrm{y}^{\mathrm{T}}{ }_{\mathrm{k}+1}, \ldots \mathrm{y}^{\mathrm{T}}{ }_{\mathrm{k}+\mathrm{f}-1}\right]^{\mathrm{T}}$ the $(\mathrm{mfx} 1)$ future data vector and $\mathrm{y}_{\mathrm{k}-1}^{-}=\left[\mathrm{y}^{\mathrm{T}}{ }_{\mathrm{k}-1}, \mathrm{y}^{\mathrm{T}}{ }_{\mathrm{k}-2}, \ldots \mathrm{y}^{\mathrm{T}}{ }_{\mathrm{k}-\mathrm{p}}\right]^{\mathrm{T}}$ the $(\mathrm{mpx} 1)$ past data vectors. The (mfxmp) covariance matrix between the future and the past is $[4-5,9-10]$

$$
H=E\left[y_{k}^{+} y_{k-1}^{-T}\right]=\left[\begin{array}{cccc}
R_{1} & R_{2} & \cdot & R_{p} \\
R_{2} & R_{3} & \cdot & R_{p+1} \\
\cdot & \cdot & \cdot & \cdot \\
R_{f} & R_{f+1} & \cdot & R_{f+p-1}
\end{array}\right]
$$

where $\mathrm{E}$ denotes the expectation operator, $\mathrm{H}$ is the block Hankel matrix (a block band counter diagonal matrix) formed with the (mxm) individual auto covariance matrices $\mathrm{R}_{\mathrm{i}}=\mathrm{E}\left[\mathrm{y}_{\mathrm{k}+\mathrm{i}} \mathrm{y}^{\mathrm{T}}{ }_{\mathrm{k}}\right]=\mathrm{CA}^{\mathrm{i}-1} \mathrm{G}$, with $\mathrm{G}=\mathrm{E}\left[\mathrm{x}_{\mathrm{k}+1} \mathrm{y}^{\mathrm{T}}{ }_{\mathrm{k}}\right]$. The auto covariance matrices are estimated from $\mathrm{T}$ data points and computed by $\hat{\mathrm{R}}_{\mathrm{i}}=\mathrm{T}^{-1} \sum_{\mathrm{k}=1}^{\mathrm{T}-1} \mathrm{y}_{\mathrm{k}+\mathrm{i}} \mathrm{y}_{\mathrm{k}}^{\mathrm{T}} ; \mathrm{i}=0,1, \ldots, \mathrm{p}+\mathrm{f}$ and with these auto covariance matrices we form the block Hankel matrix. In order to identify the transition matrix A and the output influence matrix $\mathrm{C}$ two matrix factorizations of $\mathrm{H}$ are employed: the singular value decomposition of $\mathrm{H}$ which is given by $\mathrm{H}=\mathrm{U} \mathrm{S} \mathrm{V} \mathrm{V}^{\mathrm{T}}$, with $\mathrm{U}^{\mathrm{T}} \mathrm{U}$ and $\mathrm{V}^{\mathrm{T}} \mathrm{V}$ identity matrices and $\mathrm{S}$ a diagonal matrix of singular values, and the factorization of $\mathrm{H}$ into its observability and controllability matrices [9-10]: 


$$
\mathrm{H}=\left[\begin{array}{c}
\mathrm{CA} \\
\mathrm{CA}^{2} \\
\cdot \\
\mathrm{CA}^{\mathrm{f}-1}
\end{array}\right]\left[\begin{array}{lll}
\mathrm{G} & \mathrm{AG} . . \mathrm{A}^{\mathrm{p}-1} \mathrm{G}
\end{array}\right]=\mathrm{OK}
$$

The two factorizations of the block Hankel matrix are

$$
\mathrm{H}=\left(\mathrm{US}^{1 / 2}\right)\left(\mathrm{S}^{1 / 2} \mathrm{~V}^{\mathrm{T}}\right)=\mathrm{OK}
$$

From this equation we obtain the observability matrix $\mathrm{O}=$ $\mathrm{US}^{1 / 2}$. To identify the transition matrix $\mathrm{A}$ we consider the following property, deduced from the structure of the observability matrix $\mathrm{O}$. Let $\mathrm{O}^{\downarrow}$ be the m(f-1)xn matrix obtained from $\mathrm{O}$ by deleting the last block row of $\mathrm{O}$ and let $\mathrm{O}^{\uparrow}$ be the $\mathrm{m}(\mathrm{f}-1) \mathrm{xn}$ matrix obtained from $\mathrm{O}$ by deleting the first block row of $\mathrm{O}$. We have

$$
\mathrm{O}^{\downarrow}=\left[\begin{array}{c}
\mathrm{C} \\
\mathrm{CA} \\
\cdot \mathrm{CA}^{\mathrm{f}-2}
\end{array}\right] \text { and } \mathrm{O}^{\uparrow}=\left[\begin{array}{c}
\mathrm{CA} \\
\mathrm{CA}^{2} \\
\cdot \\
\mathrm{CA}^{\mathrm{f}-1}
\end{array}\right]
$$

We obtain then

$$
\mathrm{O}^{\downarrow} \mathrm{A}=\mathrm{O}^{\uparrow}
$$

The least squares estimate of $\mathrm{A}$ is

$$
\mathrm{A}=\left(\mathrm{O}^{\downarrow}\right)^{+} \mathrm{O}^{\uparrow}=\left[\left(\mathrm{US}^{1 / 2}\right)^{\downarrow}\right]+\left[\left(\mathrm{US}^{1 / 2}\right)^{\uparrow}\right]
$$

The superscript ${ }^{+}$indicates a pseudo-inverse. The value of the matrix $\mathrm{C}$ is given by the first block row of the observability matrix $\mathrm{O}$

$$
\mathrm{C}=\mathrm{O}_{1 \mathrm{R}}=\left\{\text { first block row of }\left(\mathrm{US}^{1 / 2}\right)\right\}
$$

Once the transition matrix A has been identified its eigenvalues $\lambda_{i}$ and the matrix of eigenvectors $\Phi$ are used to identify the modal characteristics of the system: eigenfrequencies $f_{i}$, damping ratios $\zeta_{i}$ and mode shapes.

\section{Signal reconstruction}

The subspace method requires signals without aliasing to identify modal parameters, whereas tip timing data gives signals with aliasing. To solve this problem and find a link between the subspace method and tip-timing data, we propose an interpolation technique based on the use of spline functions [8]. We apply the Hilbert transform to the real signal with aliasing obtained from BTT to obtain the analytical (complex) signal $\mathrm{s}_{\mathrm{AC}}$. Using the Ries theorem [8] the interpolated signal of bandwidth $\mathrm{B}$ and center frequency $\mathrm{f}_{0}$ is :

$\mathrm{s}_{A R}(\mathrm{t})=\operatorname{real}\left[\sum_{\mathrm{k}=-\infty}^{+\infty} \mathrm{s}_{A C}\left(\frac{\mathrm{k}}{v_{\mathrm{S}}}\right) \operatorname{sinc}\left(v_{\mathrm{S}} \mathrm{t}-\mathrm{k}\right) \exp \left(\mathrm{i} 2 \pi\left(\mathrm{f}_{0} / v_{\mathrm{S}}\right)\left(v_{\mathrm{S}} \mathrm{t}-\mathrm{k}\right)\right)\right]$ where $\mathrm{k}$ is the number of samples, sinc is the sinus cardinal function and $v_{\mathrm{S}}$ the sub-sampling rate which can be much smaller than twice the highest frequency $\left(\mathrm{f}_{0}+\mathrm{B} / 2\right)$. Unfortunately, formula of this type are known to be impractical, since the sinc function decays very slowly, so that many terms of the series have to be evaluated for accurate reconstruction. An approach to avoid this problem in the complex envelope is to use reconstruction kernels $\mathrm{K}$ which are timelimited so that only a finite number of samples have to be considered. The general reconstruction formula is given by:

$$
\mathrm{s}_{A R}(\mathrm{t})=\operatorname{real}\left[\sum_{\mathrm{k}=-\infty}^{+\infty} \mathrm{s}_{A C}\left(\frac{\mathrm{k}}{v_{\mathrm{S}}}\right) \mathrm{K}\left(\mathrm{v}_{\mathrm{S}} \mathrm{t}-\mathrm{k}\right) \exp \left(\mathrm{i} 2 \pi\left(\mathrm{f}_{0} / v_{\mathrm{S}}\right)\left(v_{\mathrm{S}} \mathrm{t}-\mathrm{k}\right)\right)\right]
$$

where, $\mathrm{K}$ is piecewise continuous function. The optimum kernel for an arbitrary order $\mathrm{m}$ is given in time domain by [8]:

$$
\operatorname{Kopt}(\mathrm{t})=\sum_{l=0}^{[(\mathrm{m}-l) / 2]}(-1)^{l} \mathrm{~b}_{l \mathrm{~m}} \mathrm{~B}_{\mathrm{m}}(\mathrm{t})
$$

where, $B_{m}$ is the B-spline function of order $m$. It is a piecewise polynomial of degree (m-1) with finite support in $[-\mathrm{m} / 2$, $\mathrm{m} / 2$ ], defined recursively by:

$$
B_{m}(t)=\frac{1}{(m-1) !} \sum_{k=0}^{[m / 2-t]}(-1)^{k}\left(\begin{array}{c}
m \\
k
\end{array}\right)\left(\frac{m}{2}-|t|-k\right)^{(m-1)}
$$

and

$$
\mathrm{B}_{\mathrm{m}}(\mathrm{t})=\left(\mathrm{B}_{\mathrm{m}-1} * \mathrm{~B}_{1}\right)(\mathrm{t})
$$

is the $\mathrm{m}$-fold convolution of the rect-function, which is equal to $B_{1}$ with itself. The number $b_{l m}$ is defined as:

$$
\left(\frac{\mathrm{t} / 2}{\sin (\mathrm{t} / 2)}\right)^{\mathrm{m}}=\sum_{l=0}^{\infty} \mathrm{b}_{l \mathrm{~m}} \mathrm{t}^{2 l}
$$

\section{Evaluation of the subspace algorithm}

Figure 2 presents results obtained using the reconstruction function (26).

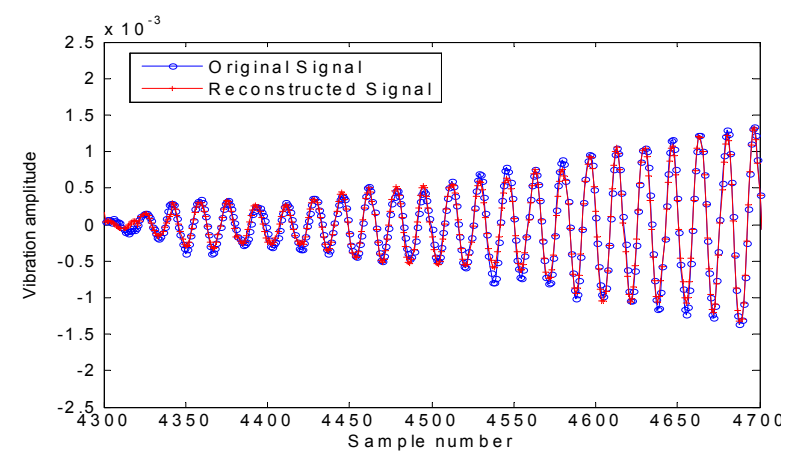

Fig. 2 Comparison between the orignal and reconstructed signal

In this figure the reconstructed signal is compared to the original signal. The error given by the 2 -norm of difference value between reconstructed and original signal is equal to $6 \times 10^{-3}$. This reconstructed signal is used in the subspace algorithm for modal parameter identification. The stability 
diagram plotting the evolution of the identified eigen-values for various orders of the system is presented in figure 3 .
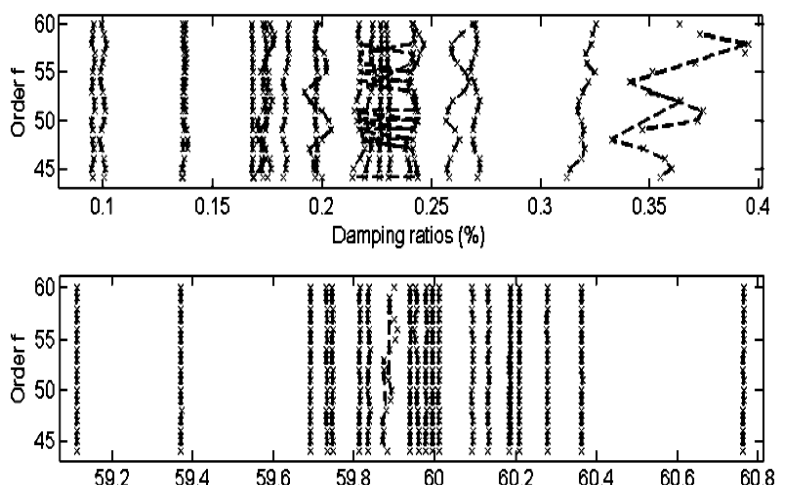

Fig.3 Stability diagrams on damping and eigenfrequencies

From these plots we can identify in the frequency band of the blades 22 eigenfrequencies and 22 damping ratios. We can see that all eigenfrequencies are stable. We plot in figures 4 and 5 the relative errors between exact and identified damping ratios and eigenfrequencies.

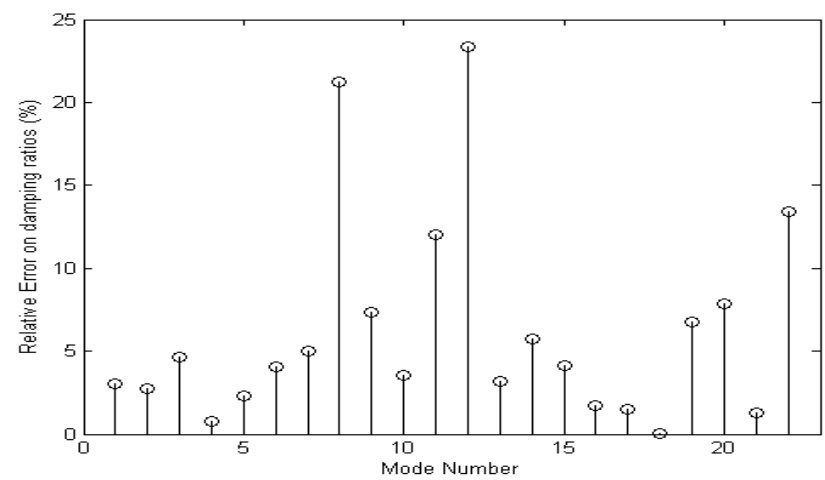

Fig.4 Relative errors on damping ratios

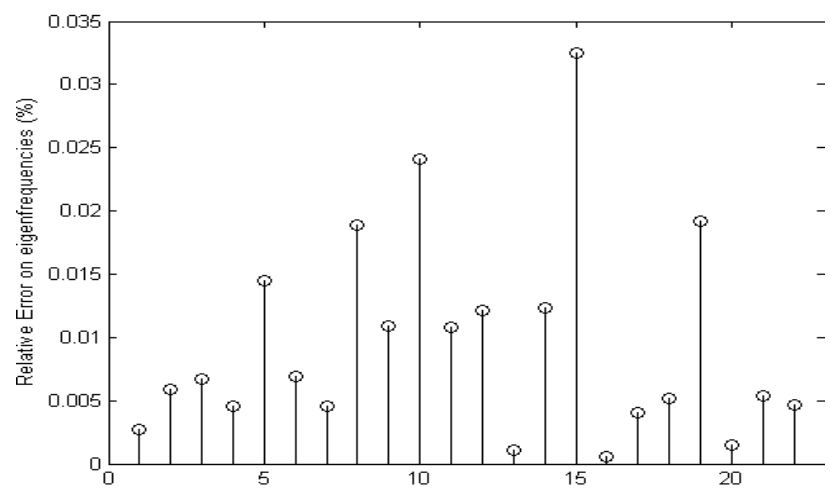

Fig.5 Relative errors on eigenfrequencies

Using the subspace method the eigenfrequencies can be identified with a reasonable error. However, the level of relative errors in damping ratios is high for certain blades. We are currently working to improve identification of damping ratios using a weighted subspace method. The exact mode shapes can be compared with the identified mode shapes using the modal assurance criterion (MAC) : let $\Phi_{\mathrm{i}}$ be the $\mathrm{i}^{\text {th }}$ exact mode shape and $\tilde{\Phi}_{\mathrm{j}}$ the $\mathrm{j}^{\text {th }}$ identified mode shape, the MAC matrix is defined as [11]:

$$
(\mathrm{MAC})_{\mathrm{ij}}=\frac{\left|\Phi_{\mathrm{i}}^{\mathrm{T}} \tilde{\Phi}_{\mathrm{j}}\right|}{\sqrt{\left(\Phi_{\mathrm{i}}^{\mathrm{T}} \Phi_{\mathrm{i}}\right)\left(\tilde{\Phi}_{\mathrm{j}}^{\mathrm{T}} \tilde{\Phi}_{\mathrm{j}}\right)}}
$$

The MAC indicates the degree of correlation between the mode shapes. For two vectors that are proportional the MAC equals 1 (perfect correlation) and values above 0,8 are very correlated. Values below 0,6 should be considered with much caution : the correlation is not well defined. Figure 6 shows the values of the MAC matrix for these 22 blades.

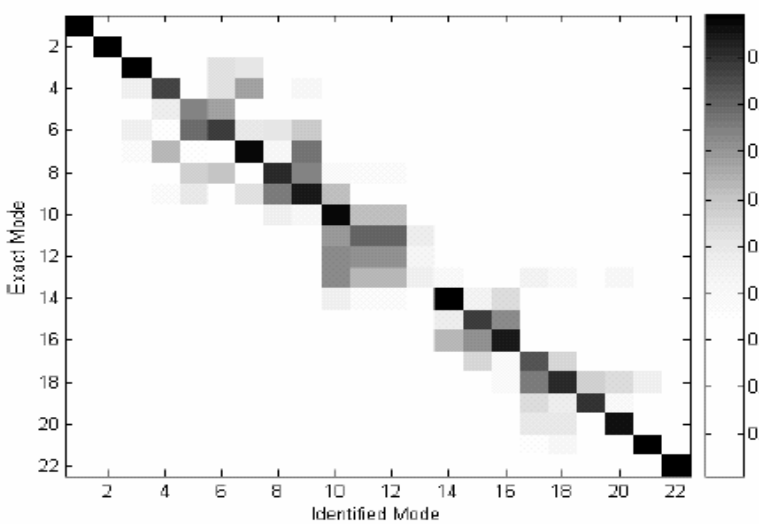

Fig.6 Comparison between mode shapes using the MAC

From this figure we can see that five modes: $5,8,11,12$ and 13 have not been found correctly by the identification process. The values of the MAC are lower than 0,6 for these five modes. For the remaining modes the correlation between exact and identified modes is acceptable or even excellent.

\section{Conclusions}

A new analysis method of blade tip timing data is proposed in this paper. This technique is based on the subspace method using the singular value decomposition of the block Hankel matrix. This method can identify very closely spaced eigenfrequencies and is a real improvement to the traditional FFT method. Despite the good results of the subspace method in eigenfrequency identification, it suffers from some disadvantages. One such disadvantage is that the subspace method, like others, is robust only if the signals are not aliased. To surpass this problem a reconstruction technique of the subsampled signal has been proposed. This reconstructed signal has been applied to the subspace algorithm. In the future we shall study the effect of signal to noise ratio in modal identification. The identification of aeroelastic coupling and aerodynamic excitation are also under investigation.

\section{Acknowledgement}

This work is supported by EDF R\&D, France. 


\section{References}

1. I. B. Carrington, J. Wright, J. E. Cooper, G. Dimitriadis, A comparison of blade tip timing data analysis methods. Jour. Aeros. Engin. 215, 301-312 (2001).

2. C.P. Lawson, P.C. Ivey, Turbo-machinery blade vibration amplitude measurement through tip timing with capacitance tip clearance probes. Sensors and Actuators A, 118, 14-24 (2005).

3. G. Dimitriadis, B. Carrington, J. WRIGHT, J.E. Cooper, Blade tip timing measurement of synchronous vibrations of rotating bladed assemblies, Mecha. Syst. and Sig. Process., 16, 599-622 (2002).

4. J.N. Juang, Applied System Identification, (Prentice-Hall, Englewood Cliffs, NJ, 1994).

5. M.Aoki, State Space Modeling of Time Series ( $2^{\text {nd }}$ Edition), (Springer-Verlag, 1990).

6. G.H. Golub, C. Van Loan, Matrix Computations (3 ${ }^{\text {rd }}$ Edition), (Johns Hopkins University Press, 1996).

7. E.F. Crawley, AGARD Manual on Aeroelasticity in AxialFlow Turbomachines: Aeroelastic Formulation for Tuned and Mistuned Rotors (1988).

8. S. Ries, Digital time-delay beam forming with interpolated signals, Sig. Process., 84, 2403-2423 (2004).

9. J. Lardies, A Stochastic realisation algorithm with application to modal parameter estimation, Mecha. Syst. and Sig. Process., 15 , 275-285 (2001).

10. J. Lardies, Estimation of parameters and model order in state space innovation forms, Inv. Probl. in Enginee., 8, 75-92 (2000).

11. L. Rigner, Modal assurance criteria value for two orthogonal modal vectors, 16th International Modal Analysis Conference, Santa Barbara CA, February 2-5 (1998). 